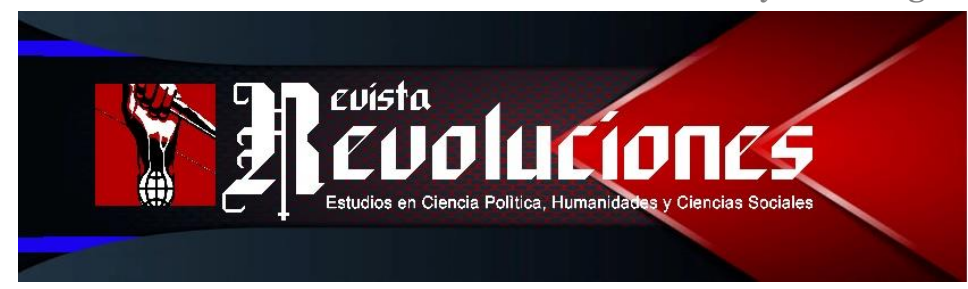

\title{
ENSAYO RESEÑA SOBRE EL TEXTO "CUATRO TESIS SOBRE EL NORTE ARGENTINO” DE MARIO ROBERTO "ROBY" SANTUCHO
}

\author{
Review essay on the text "Four theses on the Argentine North" by Mario \\ Roberto "Roby" Santucho \\ José Daniel Carabajal ${ }^{1}$ \\ UNIVERSIDAD NACIONAL DE CÓRDOBA \\ ARGENTINA \\ jdc_sgo@hotmail.com \\ https://orcid.org/o0oo-0002-3649-2890
}

DOI: https://doi.org/10.35622/j.rr.2020.02.003

Recibido: 02-III-2020 / Aceptado: 28-VI-2020 / Actualizado: 21-I-2021

\section{Resumen}

En este ensayo se analizará el texto "Cuatro tesis sobre el Norte argentino" del líder revolucionario argentino Mario Roberto "Roby" Santucho, quien fuera fundador del Partido Revolucionario de los Trabajadores (P.R.T.) y posteriormente del Ejército Revolucionario del Pueblo (E.R.P.) en la década de 1970. La importancia del texto reside en su análisis de las estructuras productivas y las clases sociales en que se encontraba estratificada la región del NorOeste Argentino (NOA), y más concretamente la provincia de Tucumán donde se concentra la mayor producción azucarera del país, y que fuera uno de los focos de resistencia revolucionaria rural más importantes.

Palabras Clave: Clase obrera, rural, conflicto social, Argentina, tesis.

\begin{abstract}
This essay will analyze the text "Four theses on the Argentine North" by the Argentine revolutionary leader Mario Roberto "Roby" Santucho, who was the founder of the Workers' Revolutionary Party (PRT) and later of the People's Revolutionary Army (ERP) in the 1970s. The importance of the text lies in its analysis of the productive structures and social classes in which the Northwest Argentine region (NOA) was stratified, and more specifically the province of Tucumán, where the largest sugar production in the country is concentrated , and that it was one of the most important centers of rural revolutionary resistance.
\end{abstract}

\footnotetext{
${ }^{1}$ Licenciado en ciencia política, licenciado en sociología, investigador en el Centro de Investigaciones Jurídicas y Sociales de la Universidad Nacional de Córdoba.
} 
Keyword: Working class, rural, social conflict, Argentina, thesis.

\section{INTRODUCCIÓN}

En este ensayo la producción azucarera y la situación de la clase obrera cañera asume la misma centralidad que la clase obrera indígena peruana en el análisis socioeconómico realizado por Mariátegui, quien fue un hombre profundamente preocupado por la problemática de los trabajadores rurales de Perú, razón por la cual comenzó a interiorizarse por las cuestiones indígenas y agrarias de su país. Casi del mismo modo, pero sin la cuestión indígena como característica central (por razón de minoría racial en Argentina, pero que igualmente si preocupó siempre a los hermanos Santucho por lo que se funda el FRIP, más adelante se profundizará al respecto),

Mario Roberto Santucho se encontraba interesado por la situación de los obreros de las plantaciones de caña de azúcar del norte de Argentina, quienes eran explotados por los terratenientes y arrendatarios. Con tales antecedentes, no es difícil ubicar a Santucho, al igual que a Mariátegui, "(...) con ramificaciones hacia el mundo sindical y el movimiento indigenista" (Terán, 2007:12).

La problemática a la que se hará mención y que será analizada con el texto del líder revolucionario argentino Mario Roberto Santucho es importante para entender el surgimiento en esta región cañera de uno de los focos revolucionarios más importantes del país, como fue el caso de la guerrilla rural desplegada por el PRT - ERP, (más allá de consideraciones de estrategia militar como la geografía montuosa y su similitud con la geografía vietnamita que alentaba el surgimiento de una guerrilla rural) cuya base social estaba sustentada por trabajadores rurales de la caña de azucarera y hacheros de los obrajes de la industria maderera durante la década de 1970. A lo descripto por el autor se fundamentará con otros autores y fuentes que sustenten o ayuden a una mejor comprensión del texto analizado, el cual es un texto ante todo de análisis económico (por la propia formación del autor, Contador Público Nacional) pero que también es eminentemente político y social por su denuncia y por el llamado a la acción.

El momento histórico del texto que se analizará se sitúa en la problemática vivenciada en Argentina durante las décadas de 1960 - 1970 (dictadura militar denominada Revolución argentina, 28 de junio de 1966 al 25 de mayo de 1973), pero que tuvo implicancias políticas, sociales y económicas muy particularmente en tiempos de la última dictadura militar en este país, (Proceso de Reorganización Nacional, desde el 24 de marzo de 1976 hasta el 10 de diciembre de 1983), y que tendrá consecuencias importantes para los trabajadores de la industria del azúcar en la región noroeste del país, principalmente en la provincia de Tucumán, ya que en esta provincia se centra el análisis del autor, puesto que allí desarrolló sus estudios académicos y gran parte de su vida y activismo social y político. 
La provincia a la cual se refiere el texto que se analizará líneas abajo es la provincia de Tucumán, que se encuentra en la región NOA (NorOeste Argentino) limita con las provincias de Santiago del Estero, Catamarca y Salta (esta última es también mencionada en el texto como otra de las mayores productoras de azúcar del país). Dicha región es descripta por el autor como una de las más empobrecidas del país por su característica de grandes latifundios dedicados al monocultivo (principalmente caña de azúcar) y producción primaria. Del mismo modo opinaba Mariátegui, según Sicilia (2007: 25) “(...) el problema de la miseria del indio era el problema de la tierra y la existencia de una estructura económico-social y política al servicio del latifundio".

\section{DESARROLLO}

\section{La figura de Mario Roberto "Roby” Santucho}

Mario Roberto "Roby” Santucho nació en la provincia de Santiago del Estero en el año 1936. Su padre Francisco del Rosario Santucho, fue abogado y en el seno familiar se vivía fervorosamente la política. En su juventud se traslada a la vecina provincia de Tucumán a estudiar Contador Público Nacional. Una vez egresado de la Universidad Nacional de Tucumán comenzó a trabajar como contable para el gremio FOTIA (Federación Obrera Tucumana de la Industria del Azúcar) que nucleaba a los trabajadores azucareros de esa provincia, en dicho trabajo pudo tomar contacto con la lamentable situación social y económica (pauperización, viviendas precarias dentro de los ingenios, pago en especies, etcétera) a la que eran sometidos los trabajadores cañeros en los ingenios azucareros (Brienza, 2006; Getselteris, 2015; Santucho, 2008; Santucho, 2009).

En esos tiempos se crea el mencionado FRIP, más precisamente en julio de 1961 (Santilli, 2007; Volonté, 2014) con la intención de trabajar junto a estudiantes y trabajadores rurales del norte argentino con la clara convicción de que el proletariado rural debía encarnar la revolución en Argentina (Mangiantini, 2014). De esta base partidaria nacería en 1965 el PRT (Partido Revolucionario de los Trabajadores), de ideología trotskista, fundado por Santucho y un grupo de simpatizantes como producto de una escisión del partido Palabra Obrera (Mangiantini, 2014).

Este partido apoyaría la lucha de los trabajadores hacheros y azucareros, tiempo más tarde, también por iniciativa de Santucho, se fundaría el ERP (Ejército Revolucionario del Pueblo) como brazo armado del PRT cuyo foco de resistencia rural más importante estaba localizado en la provincia de Tucumán (Brienza, 2006; Santucho, 2008; Santucho, 2009).

Con esto queda evidenciado que tal como lo hizo Mariátegui “(...) No solo es un divulgador de las ideas revolucionarias (...) sino que, gracias a su actividad, nace la primera organización de obreros y campesinos llamada a jugar un gran papel en el desarrollo de las luchas sociales en el país" (Sicilia, 2007:25).

Revista Revoluciones -30- Vol. 2, $\mathrm{N}^{\circ} 2$ (2020), pp. 28-44 
"Roby" Santucho muere el 19 de julio de 1976 a los 40 años abatido por el ejército golpista, en un departamento de Buenos Aires, pocas horas antes de partir al exilio en Cuba. Su cuerpo aún continúa desaparecido, pese a la incansable búsqueda que realizaron sus familiares y organizaciones de Derechos Humanos una vez restablecida la democracia en el año 1983 (Brienza, 2006; Santucho, 2008; Santucho, 2009).

\section{Contexto histórico de las "cuatro tesis sobre el norte argentino"}

Transcurre el mes de abril de 1966, fecha en que es escrito el texto "cuatro tesis sobre el norte argentino" son apenas dos meses antes de que la autodenominada "Revolución argentina" irrumpiera el orden democrático con un golpe militar al mando del General Juan Carlos Ongania.

Con este golpe militar se asestaría un duro golpe a la industria azucarera, (pero fundamentalmente a los trabajadores dependientes de dicha cadena de producción) de la provincia de Tucumán, pues lo que se buscaba era favorecer a un grupo de ingenios azucareros de las provincias de Salta y Jujuy; pero, de este modo, también se favorecía a los pocos ingenios locales que quedaron en funcionamiento (Brienza, 2006; Getselteris, 2015; Osatinsky, 2012; Santucho, 1964, 1966).

Una de las primeras medidas adoptadas por este gobierno sobre la industria azucarera de Tucumán fue ordenar el cierre forzoso de 11 de los 27 ingenios que existían en aquel entonces. Mientras que otras de las acciones emprendidas fue la de hostigar a los gremios y a los trabajadores más combativos (Brienza, 2006; Getselteris, 2015; Osatinsky, 2012; Santucho, 1964, 1966).

"Los cierres de los ingenios presentan dos intenciones claras: atacar a las organizaciones obreras recortándoles sustancialmente su capacidad de acción, por un lado, y por otro, favorecer a los ingenios del norte. Roberto Roth, participante en primera línea de los inicios de la dictadura, como colaborador cercano de Onganía, afirmó que algunas discusiones con este versaban acerca del criterio utilizado por Salimei para los cierres. Sostiene que no se trataba del tan mentado criterio "eficientista", es decir, que no respondía a la situación financiera de los ingenios. Durante el periodo 66-73 fueron cerrados once ingenios: San José, Esperanza, Los Ralos, Amalia, Lastenia, Mercedes, San Antonio, Nueva Baviera, Santa Lucia, San Ramón y Santa Ana (a los que posteriormente se sumaría el San Pablo), sin que se halle criterio homogéneo para tal decisión. Entonces, ¿Cuál pudo haber sido la razón utilizada para semejante destrucción?” (Getselteris, 2015. p. 40).

En la provincia de Tucumán se desarrolla la principal actividad azucarera del país, por lo que este tipo de medidas tiene como intencionalidad primaria garantizar la hegemonía de ciertos ingenios (pequeños y medianos) cerrando de este modo a los posibles competidores de los ingenios más capitalistas garantizando, por la fuerza y el disciplinamiento gremial, el 
oligopolio de un número reducido de ingenios a los cuales las Fuerzas Armadas pretendían beneficiar. Del mismo modo esta situación de cierre de los ingenios generaba la migración de los trabajadores desocupados por el cierre de sus lugares de trabajo, además de servir para castigar a los trabajadores de los gremios más combativos. Estos trabajadores tuvieron que mudar a la propia capital provincial, generando de este modo nuevos cordones de marginalidad, o en el peor de los casos, migrar de provincia por su propia subsistencia, o porque eran perseguidos por grupos policiales o paramilitares (Brienza, 2006; Getselteris, 2015; Osatinsky, 2012; Santucho, 1964, 1966).

Para completar las medidas represivas se procedió a la ocupación de los ingenios por parte de las fuerzas de seguridad nacional. Esta situación tuvo su respuesta más enérgica de la mano de los mismos trabajadores y no de la FOTIA como se esperaba. Así es como ex empleados de otros ingenios se solidarizaron con sus compañeros de las fábricas asaltadas, desgraciadamente fueron brutalmente reprimidos (Brienza, 2006; Getselteris, 2015; Osatinsky, 2012; Santucho, 1964, 1966).

"La manifestación más evidente de la barbarie cometida en Tucumán reveló su máxima expresión a través del despliegue represivo montado para garantizar los cierres: Gendarmería y Policía Federal tomaron por asalto, el mismo 22 de agosto por la madrugada, los ingenios" (Getselteris, 2015. p. 43).

Así fue que se sucedieron numerosas muertes en diferentes manifestaciones, hasta que finalmente la FOTIA se vio obligada a tomar una actitud más intransigente de cara a la defensa de los trabajadores nucleados en dicha central obrera. A partir de este momento la central sindical se vio obligada a tomar participación en varias marchas y actos de protesta iniciadas por los trabajadores (Santucho, 2008; Santucho, 1964, 1966).

Todo este contexto represivo indirecto de la actividad gremial cañera, que incluía cierre de ingenios, se completaba con acciones directas como el accionar de grupos parapoliciales que se encargaban de secuestrar, torturar y hostigar a los trabajadores. En tal sentido estas acciones directas estaban complementadas por mitos y leyendas populares desde antaño que reforzaban la dominación simbólica y cultural mediante el miedo a esa clase social. Tales mitos y leyendas tomaban el nombre de "el perro familiar" o el de los "perdidos" que no eran otra cosa que la representación simbólica de los desaparecidos. Dichos mitos aludían a que la desaparición de los trabajadores (que siempre eran los más sindicalizados y más combativos) se debía a la existencia de un perro de grandes dimensiones que emergía de los cañaverales y se fagocitaba a los trabajadores "problemáticos" del ingenio, de igual modo la leyenda de los "perdidos" aludía a obreros que se extraviaban en la espesura de las plantaciones y no eran encontrados nunca más (Santucho, 2008).

En todo este contexto de crisis regional, descripto previamente, es que surge el texto "Las cuatro tesis sobre el norte argentino" en el cual el autor describe la problemática del sector azucarero del noroeste argentino describiendo sus características estructurales y los cambios

Revista Revoluciones -32- Vol. 2, Nº 2 (2020), pp. 28-44 
que se fueron danto en la estructura productiva de esa región argentina. Al mismo tiempo realiza una detallada descripción de las clases sociales de la región y su incidencia en la problemática de la producción de la caña de azúcar. Para cerrar con sus consideraciones sobre los partidos políticos y su relación con la clase obrera cañera (Brienza, 2006; Getselteris, 2015; Osatinsky, 2012; Santucho, 1964, 1966).

\section{Análisis del texto "cuatro tesis sobre el norte argentino"}

El siguiente texto que se analizará es definido por el propio autor como un documento político (Santucho, 1966), es decir un trabajo doctrinario (podría decirse) destinado a concientizar a la clase obrera de la región noroeste del país, en donde se concentra la mayor actividad azucarera de la Argentina.

El texto se divide en cuatro tesis donde el autor desarrolla su pensamiento en clave de estructura social y económica, vinculando su análisis con la posibilidad de apoyo por parte de la clase trabajadora de la caña de azúcar para enlistarse en las filas de PRT - ERP esbozando lineamientos que sirven de guía de acción sobre cómo proceder al respecto.

El texto se presenta como un documento del Partido Revolucionario de los Trabajadores (P.R.T.) en el cual se analiza la situación de las empresas capitalistas y el rol que deben desempeñar los trabajadores en su lucha contra el capitalismo nacional y el imperialismo extranjero. El texto se encuentra dividido en cuatro tesis que dan nombre al mismo.

\section{Tesis 1) la estructura económica del noroeste}

En esta primera tesis el autor (Santucho, 1966) explica el surgimiento de las clases sociales en el noroeste argentino, y como los terratenientes lograron llegar al monocultivo de tal forma que convirtieron a Tucumán en un enclave del cultivo de la caña de azúcar, a la cual luego se incorporara a la producción cañera la provincia de Salta.

Tal como fuera expresado anteriormente, la estructura social y económica de la región noroeste de Argentina tuvo su conformación en las postrimerías del siglo XIX, cuando los terratenientes decidieron dedicarse al monocultivo de la caña de azúcar en la provincia de Tucumán.

$\mathrm{Al}$ respecto Santucho (1966):

"El hecho histórico y contemporáneo del desarrollo capitalista en el norte argentino fue y es la industria azucarera. La incorporación de esta región al conjunto del desarrollo capitalista nacional, producida a fines del siglo pasado, con el catalizador del ferrocarril que, al acortar distancias y vincular de manera ya indisoluble las economías pre-capitalistas del noroeste al mercado nacional, dio un golpe de muerte a la diversificada producción artesanal y agrícola, y reoriento la economía hacia la mono producción capitalista. A partir de entonces la economía se basó en la incipiente industria azucarera que adquirió un impresionante ritmo

Revista Revoluciones -33- Vol. 2, No 2 (2020), pp. 28-44

Esta obra está bajo una licencia internacional Creative Commons Atribución 4.0.

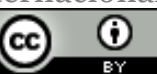


de desarrollo y concentración, convirtiéndose en el abastecedor nacional de azúcar del país. La producción nacional de azúcar pasó de 1.400 toneladas en 1872 a 336.000 en 1914 " (Santucho, 1966).

Esta situación termino de configurar a Tucumán como epicentro del crecimiento económico en el noroeste argentino, pues la actividad azucarera se convirtió en el motor del desarrollo capitalista del norte con una mano de obra muy barata, y con la tecnificación que amenaza despedir empleados y de este modo abaratar más los costos de la producción cañera (Brienza, 2006; Getselteris, 2015; Osatinsky, 2012; Santucho, 1964, 1966).

"Pero en el conjunto del noreste fue sin duda determinante el peso específico de la industria azucarera que al concentrarse en Tucumán la convirtió en la provincia con mayor desarrollo capitalista de todo el noroeste, y en su metrópoli. Esta etapa que podemos situar entre los años 1880 y 1900 se caracteriza justamente por el ascenso de Tucumán a uno de los primeros lugares en cuanto a desarrollo capitalista en el país" (Santucho, 1966).

Históricamente desde que los primeros conquistadores llegaron a tierras de lo que hoy es territorio argentino, a través del denominado "Camino real" provenientes del Alto Perú, Tucumán fue el centro de operaciones que los conquistadores establecieron para continuar sus actividades en la región que hoy conocemos como N.O.A. (NorOeste Argentino) (Garay, 2008; Castiglione, 2012; Floria, \& García Belsunce, 1992).

Teniendo en cuenta la importancia histórica de Tucumán como nexo directo entre lo que actualmente se conoce como NorOeste Argentino y el antiguo Virreinato del Río de la Plata es posible apreciar según el análisis de Santucho (1966) que en tiempos modernos y contemporáneos la provincia de Tucumán siguió manteniendo la importancia que tradicionalmente tenía como punto estratégico para la conquista y posteriormente en la época colonial (Garay, 2008; Castiglione, 2012; Floria, \& García Belsunce, 1992).

Convertida como epicentro del conocimiento científico del norte argentino, a través de sus prestigiosas universidades, Tucumán lideró también la nueva reconversión del dominio otrora conquistador ahora capitalista convirtiéndose en la nueva versión de la capital de la producción en la región del noroeste argentino, solo que, bajo los nuevos ropajes del capitalismo destinada a liderar el crecimiento económico de la región, y tal como lo hizo la conquista antes, dejando despojos de feudalismo, pobreza y marginalidad; Santucho (1966) observa que en Tucumán coexisten restos del feudalismo con capitalismo avanzado del mismo modo que “(...) Mariátegui concibe la formación económica y social de su país en tanto unidad, en la cual se combinan tres modos de producción articulados de manera particular (...)” (Sicilia, 2007: 69).

“(...) Las primeras décadas de este siglo marcan la incorporación de Jujuy y Salta a la producción azucarera, la que se produce a iniciativa del capital extranjero, fundamentalmente inglés. Desde el comienzo de la industria azucarera de salta y Jujuy comienza pisando fuerte, en fábricas más modernas que las tucumanas, con plantaciones de

Revista Revoluciones -34- Vol. 2, No 2 (2020), pp. 28-44 
tipo altamente capitalistas, fundamentalmente disimiles a la estructura agrícola tucumana signada por la presencia de cañeros chicos medianos. (Que aportan un elevado porcentaje de la materia prima). En Salta y Jujuy prácticamente no existen cañeros (el grueso de las plantaciones son propiedad de las empresas que poseen los ingenios) lo que hay son grandes, también con plantaciones de tipo capitalista, plantaciones que son verdaderas fábricas, con sus estaciones de máquinas, su taller, concentración proletaria.” (Santucho, 1966).

Con el establecimiento de Tucumán como nuevo enclave capitalista de la industria azucarera entraron a complementar la explotación nuevos actores, que, con capitales extranjeros, se instalaron en la región norte, al límite con Bolivia en las provincias de Salta y Jujuy. Este proceso de acumulación capitalista en Salta y Jujuy fue inverso que, en Tucumán, pues mientras que en Tucumán las formaciones capitalistas sugieren un proceso de características de acopio en la cual existen grandes terratenientes que producen la materia prima en sus campos y luego venden la caña a los ingenios. Mientras en las provincias de Salta y Jujuy el proceso se dio de modo inverso, fueron los grandes ingenios apoyados por capitales extranjeros los que comenzaron a tener sus propias plantaciones de caña de azúcar (Brienza, 2006; Getselteris, 2015; Osatinsky, 2012; Santucho, 1964, 1966).

\begin{abstract}
"En estas tres provincias el desarrollo del capitalismo es muy elevado, forman entre las más desarrolladas del país. Y en su conjunto aportan más del 90\% de la producción azucarera nacional. Están unidas por esa característica común: la producción azucarera. Pero mientras en Tucumán se encuentra estancada, aproximadamente desde hace más de treinta años, cuando se detuvo la expansión de la industria ante el triple dique de la saturación del mercado nacional, la imposibilidad de exportar, y la incorporación a la producción azucarera de Salta y Jujuy, no solamente estancada a partir de 1957 en una crisis estructural sin salida capitalista, Salta y Jujuy continúan su expansión, se caracterizan por un capitalismo pujante, en desarrollo, no solamente en la producción azucarera, sino en otras importantes ramas. (Petróleo, ganadería, agricultura y siderurgia)" (Santucho, 1966).
\end{abstract}

Es posible apreciar de este modo la conformación de tres nodos de producción azucarera que son las provincias de Salta, Jujuy y Tucumán. Las dos primeras caracterizadas por la alta tecnificación y la incorporación de capitales extranjeros, y Tucumán con un modo de producción que gira en torno a la explotación de los trabajadores cañeros. Por aquel entonces la fuerza productiva que impulsaba la economía de la región estaba centrada en la actividad azucarera, esto por dos razones: la primera la gran extensión de tierra que acumulaban los terratenientes ligados a la industria azucarera, y la segunda por la baratez de la mano de obra de los trabajadores cañeros (Getselteris, 2015; Osatinsky, 2012; Santucho, 1964, 1966).

\title{
Tesis 2) las clases sociales
}

En esta segunda tesis el autor desarrolla una minuciosa descripción de todas las clases sociales involucradas en la producción azucarera y su implicancia en la estructura económica y social de la región. Asimismo, realiza un análisis de las posibilidades de cada clase de constituirse en aliada para la revolución. 
En su escrito el autor (Santucho, 1966) comienza con la descripción desde el vértice superior de la pirámide hasta la base constituida por la clase obrera cañera a la cual califica como la única capaz de llevar adelante el proceso revolucionario, concretamente la lucha armada.

"1) la oligarquía terrateniente, que posee alrededor del $75 \%$ de la tierra cultivada, a pesar de constituir el $5 \%$ por ciento de los propietarios de la tierra, es la clase más retardaría, parasitaria, de la sociedad, aunque carece de políticas propias independientes, dado que en su aplastante mayoría está ligada, es una misma cosa, con la burguesía oligárquica azucarera, que defiende entonces también los intereses de los terratenientes. En salta, como excepción, la oligarquía terrateniente conserva aún gran influencia y da su tónica ideológica, (un catecismo ultraconservador) a toda la ideología dominante. Pero debe quedar claro que no existen contradicciones entre la oligarquía terrateniente y la burguesía oligárquica de los ingenios" (Santucho, 1966).

Esta situación descripta por el autor se puede definir como una "simbiosis activa" (Sidicaro, 1982) entre la oligarquía terrateniente y la burguesía industrial propietaria de los ingenios, esta alianza de clases tenía la particularidad de perjudicar a la clase obrera, pues quienes siempre obtenían beneficios por parte del gobierno eran estas dos clases, mientras que los trabajadores cañeros solo obtenían un mínimo incremento en sus salarios.

La segunda clase analizada por Santucho es la burguesía oligárquica azucarera. Un escalón más abajo en la pirámide de la estructura socioeconómica de la región. Se trata de una clase estrictamente vinculada a la industria azucarera, independientemente de la posesión de tierras tal como era la característica definitoria de la anterior clase.

“2) la burguesía oligárquica azucarera: es el gran patrón del norte, controla el grueso de la vida económica y subordina a sus intereses a amplios sectores de la burguesía comercial, agrícola, ganadera e industrial de las provincias azucareras. En consecuencia, es un gran enemigo de las clases explotadas del país, sus vinculaciones económicas con el imperialismo, del que es socia en la propiedad de varios ingenios, y con la oligarquía y la gran burguesía del litoral, da respaldo nacional, la muestra como uno de los pilares del régimen capitalista argentino. En la disputa por el mercado, se produce varias y frecuentes roces entre los distintos sectores de esta clase" (Santucho, 1966).

Esta es señalada por Santucho como la gran organizadora del sistema económico capitalista del Norte argentino por la gran influencia de su producción azucarera sobre la región y sus vínculos con otras regiones (Brienza, 2006; Getselteris, 2015; Osatinsky, 2012; Santucho, 1964, 1966).

La tercera clase analizada es el imperialismo ligado a los grandes capitales extranjeros y que diversifican sus actividades capitalistas en la rama azucarera, llegando a acaparar varios eslabones productivos en una sola concentración capitalista. Cabe aclarar que cuando el autor, en este texto (Santucho, 1966), se refiere al imperialismo como clase lo hace en alusión a la gran burguesía dedicada a la agroindustria vinculada a la cadena de producción azucarera.

Revista Revoluciones -36- Vol. 2, No 2 (2020), pp. 28-44

Esta obra está bajo una licencia internacional Creative Commons Atribución 4.0. 
“3) el imperialismo, posee varios ingenios, fábricas, minas y fincas, en algunos casos en sociedad con la burguesía oligárquica del azúcar, así como en bancos y otras empresas. Su presencia como socio mayor de la patronal azucarera confirma su papel de gran expoliador del país y de los trabajadores" (Santucho, 1966).

Esta clase posee intereses diversificados que le permiten acomodarse a cualquier coyuntura política y económica con el objeto de extraer plusvalor a través de sus empresas. A través de la integración vertical de sus intereses logran extraer plusvalor en los diferentes eslabones de la cadena productiva (Getselteris, 2015; Osatinsky, 2012; Santucho, 1964, 1966).

Es decir que la extracción comienza con el trabajador cañero a través de la posesión de tierras cultivadas, continua con la posesión de los ingenios donde se realiza la molienda de la caña, para luego continuar con la cadena de distribución y así sucesivamente con el dominio de toda la cadena de producción, industrialización, distribución y comercialización (Getselteris, 2015; Osatinsky, 2012; Santucho, 1964, 1966).

“4) la burguesía mediana, es una clase contradictoria, que por una parte encuentra su horizonte restringido por el tampón oligarquía - burguesía oligárquica azucarera imperialismo, que plantea desarrollar nuevos rubros de explotación, intenta profundizar y extender el desarrollo capitalista, intento en que choca con la clase explotadora tradicionales, lo que provoca serios roses con dichas clases. Pero por otra parte como explotadora del trabajo asalariado, como clase propietaria, se encuentra en una contradicción crucial, permanentemente en brazos de la gran patronal" (Santucho, 1966).

Esta burguesía mediana se puede encontrar en cualquier eslabón de la cadena antes descripta, pues está en el medio de la pirámide de la estructura socioeconómica, esta característica hace que este en permanente pugna de intereses con quienes están arriba suyo, pues busca abrirse lugares entre la burguesía oligárquica azucarera, la burguesía terrateniente, y algún espacio del imperialismo. El conflicto se genera cuando las clases que se encuentran más arriba en la pirámide no admiten que esta clase en ascenso dispute sus lugares de privilegio.

Mientras que con las clases que se sitúan en la base de la pirámide los conflictos se dan a nivel de patronal y trabajadores, mediados por los gremios como FOTIA. Esta pugna de intereses se representa, del lado de los trabajadores, por el aumento de salarios, mejoras en las condiciones de trabajo, cese de despidos, etcétera. Mientras que los intereses en pugna que defiende la patronal están relacionados con el logro de la eficiencia económica y la rentabilidad de las inversiones, la incorporación de mano de obra barata, abaratamiento de los costos, inclusión de tecnificación, en definitiva, todas cuestiones que perjudican a la clase obrera cañera (Getselteris, 2015; Osatinsky, 2012; Santucho, 1964, 1966).

“5) la pequeña burguesía urbana constituida por profesionales, comerciantes, talleristas, artesanos, empleados y estudiantes, simpatiza en general con la clase obrera y sus luchas, fundamentalmente los empleados y una vanguardia importante del movimiento estudiantil. La crisis general del país, unida a la coyuntural de la industria azucarera es la base de

Revista Revoluciones -37- Vol. 2, № 2 (2020), pp. 28-44 
sustentación de la radicalización de ese sector medio. El proletariado debe darse una política hacia estos sectores para convertirlos en sus aliados, ya que por sí solos son incapaces de enfrentar al imperialismo y a la gran patronal argentina en forma consecuente. Las posibilidades de que la clase media sea utilizada como carne de cañón contra el proletariado, en las condiciones actuales, son mínimas" (Santucho, 1966).

Esta clase suele tener una confluencia transitoria de intereses (Sidicaro, 1982) con la clase cañera toda vez que son afectados en diferentes medidas por la suba de los precios, la baja de salarios, lo que se refleja en una solidaridad de clase en los actos de protesta convocados por centrales sindicales afines.

Finalmente, el autor analiza las dos clases más bajas de la estructura de la producción cañera, por un lado, desagrega a quienes serían una capa superior dentro de los más bajos a los que denomina "campesinado de la zona”, a los que subclasifica según la extensión de tierra y modo de cultivo. "6) el campesinado de la zona presenta características dispares, por lo que podemos dividirlos en cuatro grandes grupos; a) burguesía mediana; b) pequeños agricultores, quinteros, etcétera; c) cañeros; d) campesinado pre-capitalista" (Santucho, 1966).

El primer grupo será excluido del presente análisis puesto que no se refiere a una categoría de campesinado cañero, así lo aparta el propio autor al referirlo al grupo 4, es decir al de la burguesía mediana, categoría está en la cual se incluye también a los cañeros grandes, por tanto, se abordará la descripción y análisis de los cañeros pequeños y medios.

"En el grupo a) podemos incluir a los ganaderos, al campesinado que trabaja sus explotaciones con medios mecánicos, en zonas de riego o de lluvia muy abundantes y en su totalidad para el mercado. Este grupo de campesinos debe ser incluido por su comportamiento de clase en el grupo 4). Los del grupo b) producen también para el mercado fundamentalmente, pero no poseen medios mecánicos, son en su mayoría arrendatarios, y son explotados por los mayoristas y acopiadores. Son potencialmente aliados de la clase obrera, por su dinamismo, concentración, organización, y combatividad, y por sus intereses inmediatos coinciden con suma frecuencia con los obreros del azúcar. (Nos referimos a los cañeros chicos fundamentalmente, y a los medianos, los cañeros grandes deben ser incluidos también el punto 4)" (Santucho, 1966).

Tomando en cuenta un padrón de la Dirección Nacional del Azúcar elaborado en el año 1963 en el cual para el año 1965 (fecha más aproximada a la escritura del texto que se analiza) existían 18.602 cañeros, mientras que para la UCIT registraban 23000 cañeros. En ese tiempo se consideraba que una finca cañera resultaba rentable para la subsistencia de una familia tipo, cuando la superficie sembrada oscilaba entre las 14 y las 20 hectáreas, esto es interesante para comprender el grado de pauperización de la clase cañera tucumana, pues de los 18.602 cañeros del censo mencionado anteriormente, 13.000 poseían superficies sembradas menores a 5 hectáreas siendo el mínimo para la subsistencia de 20 hectáreas (Osatinsky, 2012; Anónimo, s/f).

Revista Revoluciones -38- Vol. 2, No 2 (2020), pp. 28-44 Esta obra está bajo una licencia internacional Creative Commons Atribución 4.0. 
"En cuanto al grupo d) compuesto por aquellos agricultores y criadores de las zonas más atrasadas de las provincias norteñas, que utilizan métodos no mecánicos de cultivo y cosecha, que producen para su propio consumo y no están integrados al mercado capitalista, son también potenciales aliados de la clase trabajadora, la que debe agotar esfuerzos para incorporarlos en su lucha, sacándolos del atraso en que se encuentran” (Santucho, 1966).

Bajo este grupo se encontraban un indefinido de agricultores varios y criadores de ganado diversos por lo tanto no se hará consideraciones al respecto puesto que se trata de analizar el sector cañero en su especificidad.

“7) la clase obrera, es la más revolucionaria de la sociedad, y la que encabeza a los sectores populares en la lucha por la liberación nacional y social de nuestra patria y de los explotados por que tiene intereses directa y totalmente contrapuestos con la patronal nacional y el imperialismo. El núcleo de la clase obrera norteña, su sector más combativo es el proletariado azucarero, así quien debe dirigir nuestro partido sus esfuerzos fundamentales, como lo está haciendo actualmente. Existen también fuertes núcleos de obreros urbanos (metalúrgicos, textiles, ferroviarios, cerámicos, transportes, vitivinícolas, construcción, etcétera), los que juegan y jugaran un rol de gran importancia: un numeroso proletariado agrícola muy desorganizado, pero que tiene asimismo suma importancia; el proletariado forestal que para el caso de Santiago es fundamental y el proletariado de minas y canteras" (Santucho, 1966).

La clase obrera cañera se caracteriza por la utilización de mano de obra familiar, es decir, como ya se mencionó anteriormente, lo que predomina es la agricultura familiar con superficies sembradas, que, al ser tan pequeñas, no requiere de gran cantidad de mano de obra. Las condiciones de vida del proletariado cañero eran deplorables, la casi totalidad habitaba viviendas precarias construidas de barro y paja en las cuales las familias vivían en condiciones de hacinamiento, sin servicios de energía eléctrica ni agua potable (Getselteris, 2015; Santucho, 2008).

Concretamente la clase obrera cañera, en este caso tucumana por la característica casi de monocultivo de la caña de azúcar en dicha provincia, se constituyó desde sus inicios como una clase social en permanente conflicto (generalmente toma de fábricas y plantaciones), incluso desde antes de la existencia de sus representantes corporativos como los sindicatos, en su caso la FOTIA, en su construcción histórica como clase obrera estuvo presente el conflicto con la patronal y los terratenientes, donde el elemento de subordinación de quienes se dedicaban a la plantación de la caña de azúcar al sistema agroindustrial estuvo dado por el contrato de compra - venta de la materia prima por parte de los ingenios a los pequeños productores (Getselteris, 2015; Osatinsky, 2012; Santucho, 1964, 1966).

Uno de los puntos aglutinantes como clase fue el precio de la caña de azúcar, sobre el cual tuvieron fuerte incidencia los conflictos con los empresarios, con el Estado nacional en su búsqueda por unificar el precio de la caña de azúcar y los subsidios al sector, con el gobierno provincial con quien mantuvieron diferencias sobre a qué ingenios debían vender su producción, ¿debían venderlo a los ingenios de Tucumán? ¿O debían venderlo a los ingenios de Salta y Jujuy? Todo esto estuvo influenciado por los acuerdos entre los gobernantes en

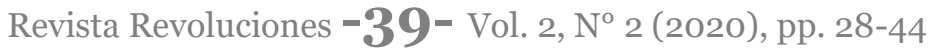


aquel entonces y los dueños de los medios de producción, siempre en detrimento de los pequeños productores y la clase obrera (Brienza, 2006; Getselteris, 2015; Osatinsky, 2012; Santucho, 1964, 1966).

El respecto el pensamiento de Mariátegui era en idéntico sentido:

"Por tanto, indica Mariátegui -es el primero en hacerlo-, la revolución latinoamericana exige la dirección proletaria, clase minoritaria que necesita por tanto ampliar su base política y buscar aliados en otras clases, pero jamás en la burguesía sino en el campesinado. Esto es, en el indio, que en su idea constituye en sí y por si una clase-nación” (Sicilia, 2007: 71).

Luego de haber analizado, según el texto del autor, las características de la estructura socioeconómica del norte argentino (concretamente las provincias de Salta, Jujuy, y Tucumán, enclaves del capitalismo azucarero argentino) y de haber conocido su implicancia para la clase obrera cañera, es menester identificar, según Santucho (1966), otras características que tiene que ver con la estructura política y sus posibilidades de acción en la clase obrera.

\section{Tesis 3) otras características}

En esta tercera tesis el autor analiza cuestiones sociopolíticas que versan sobre los partidos políticos de izquierda, y su dificultad de penetración en la sociedad argentina y más específicamente en la provincia de Tucumán. "Los partidos de izquierda son prácticamente inexistentes. Y no por dificultad de penetración, sino por carecer de una línea política a la altura de las circunstancias, y por la escasa militancia en la base" (Santucho, 1966).

Esto es así toda vez que en la República Argentina los principales partidos políticos fueron fundados por sectores de la clase media, sus principales líderes fueron argentinos (no como en el caso de los partidos de izquierda que fueron importados de Europa con las corrientes inmigratorias) como el caso de la Unión Cívica Radical (U.C.R.) fundada por Leandro Alem, y por Juan Domingo Perón en el caso de Partido Justicialista (P.J.), estos dos partidos fueron históricamente hegemónicos en contiendas electorales, por lo tanto en ocupar los cargos e instrumentos del Estado (Floria, C. y García Belsunce, C.;1992).

Esto explica la razón de que partidos como el PS (Partido Socialista), PC (Partido Comunista) o hasta el propio PRT no tuvieran una inserción tal como lo plantea el autor. Únicamente algunos sectores de las clases trabajadoras fueron adherentes a estos partidos, muchos fueron cooptados por el peronismo y sus políticas asistencialistas por lo cual perdieron su tradición de militancia en partidos de izquierda. "En general, en la Región la tradición de izquierda es mínima, salvo en Tucumán donde la clase obrera, particularmente el proletariado azucarero es heredero de una rica tradición marxista" (Santucho, 1966). Esta es la razón por la cual el líder del PRT - ERP ordena poner todos los esfuerzos de su partido en captar la afiliación de los trabajadores cañeros, principalmente por ser, dentro de las clases obreras antes mencionadas, la más pobre y la más proclive a soluciones marxistas, dado su alto grado de

Revista Revoluciones -40- Vol. 2, $\mathrm{N}^{\circ} 2$ (2020), pp. 28-44 
explotación como clase por parte del capitalismo terrateniente. Se vuelve evidente que Santucho reconocía en la clase obrera cañera, la más pauperizada de la región, tenía ese potencial revolucionario que Marx, y más próximos Mariátegui, esperaba y anticipaba que sería la clase que derrotaría al capitalismo e instauraría el socialismo y luego el comunismo (Brienza, 2006; Getselteris, 2015; Osatinsky, 2012; Santucho, 1964, 1966).

\section{Tesis 4) las tareas generales de nuestro partido}

En esta última tesis el autor traza un plan de acción acerca de las tareas que, según el autor, y su fundador, los miembros del P.R.T. deben realizar con las distintas clases sociales y para con el campesinado cañero en particular, para lograr su adhesión.

"De la caracterización que antecede surge claramente que el lugar de trabajo fundamental que el PRT, en el norte, es en estos momento, el proletariado azucarero de Tucumán, Salta y Jujuy, hacia el que debemos dirigir nuestro mejor esfuerzo, formando militantes y equipos en los ingenios, colonias y lotes, logrando cada vez mayor influencia en las organizaciones sindicales, interviniendo en cada acción de los trabajadores, en cada conflicto, para elevar incesantemente la conciencia de la clase y profundizar a cada paso el contenido de la lucha" (Santucho, 1966).

La clase obrera cañera posee el dinamismo propio de una clase pauperizada y movilizada que se necesita para hacer frente en las esferas de lo social y de lo político, esa capacidad de establecer alianzas y la ferocidad de sus trabajadores a la hora de plantear sus reclamos (Brienza, 2006; Getselteris, 2015; Osatinsky, 2012; Santucho, 1964, 1966).

Esto sumado a la combatividad de FOTIA, en su dimensión gremial, hacen de los trabajadores cañeros una clase que reúne las características que los partidos revolucionarios de izquierda necesitan para emprender acciones armadas, y no por casualidad, sino por la causalidad de las razones antes expuestas, el epicentro de la lucha armada rural en Argentina se desarrolló donde existía una fuerte presencia de la clase obrera cañera, es decir en Tucumán, Salta y Jujuy (Getselteris, 2015).

"Así mismo debemos prestar primerísima atención al proletariado urbano, al proletariado agrícola, al proletariado de minas y canteras, especialmente los metalúrgicos de Jujuy y los petrolíferos de salta, también parte de la clase obrera y a quienes debemos esforzarnos por organizar en torno a los azucareros. En el caso especial de Santiago, el trabajo fundamental en la provincia debe dirigirse al proletariado forestal que es el único capaz de desarrollar acciones de trascendencia en dicha provincia" (Santucho, 1966).

Está claro que para el líder del P.R.T. - E.R.P. el trabajo revolucionario debía comenzar por el norte del país, región esta que Santucho conocía muy bien, pues nació, vivió y recorrió esta zona del país lo suficiente como para comprender cuales eran las clases sociales más explotadas en cada una de las provincias. Concretamente se refiere a las provincias cañeras, Salta, Jujuy y Tucumán. En referencia a Santiago del Estero incluye a la clase obrera de la 
industria forestal por ser esta la actividad más explotadora en dicha provincia, asignándoles capacidad de realizar acciones de trascendencia, es decir acciones de lucha armada (Brienza, 2006; Getselteris, 2015; Osatinsky, 2012; Santucho, 1964, 1966).

"Con respecto a los campesinos cañeros, que caracterizamos como el aliado fundamental de la clase obrera en el norte, debemos tener una política clara de alianza que no puede surgir sino de un profundo trabajo sindical y político en dicho sector" (Santucho, 1966).

El trabajo sindical al que alude Santucho es el que realizó él mismo en su primer empleo como contable, pues una vez recibido comenzó a trabajar en el gremio FOTIA donde tomó contacto con la realidad de los trabajadores azucareros y el grado de explotación a que estos eran sometidos.

Otra de las actividades emprendidas por el PRT significó la inserción de sus partidarios en las actividades gremiales de los gremios vinculados a las actividades antes descriptas.

"En cuanto al campesino atrasado, a pesar de su poco peso económico, es también aliado potencial de importancia para la clase obrera y debemos realizar sobre el todo un trabajo propagandístico por medio de los trabajadores rurales, ligados a nuestro trabajo sobre el proletariado rural" (Santucho, 1966).

Del mismo modo, era común ver a miembros del PRT ofreciendo volantes o panfletos en las puertas de las fábricas e ingenios a la salida de los obreros. Esto se realizaba con el objeto de concientizar sobre la situación social y sobre la doctrina del partido y su línea de acción revolucionaria. También se realizaban foros y ateneos de discusión en los barrios de los trabajadores, donde se discutía los problemas de la clase obrera y se reclutaba seguidores para el PRT (Brienza, 2006; Getselteris, 2015; Osatinsky, 2012; Santucho, 1964, 1966).

"Simultáneamente nuestro partido debe volcarse al estudiantado y por esa vía a toda la pequeña burguesía urbana. La importancia del movimiento estudiantil es inmensa, a pesar de sus limitaciones, porque de él surgen gran parte de los dirigentes revolucionarios que se fusionaran con las clases obreras" (Santucho, 1966).

Con los mismos destinatarios y con idéntico sentido revolucionario que Mariátegui refleja en la revista Amauta (Sicilia, 2007) "El tono desafiante y la orientación revolucionaria de Amauta -que circula en talleres, en fábricas, el campo, las minas y las universidadescomienzan a inquietar al régimen (...)" (Sicilia, 2007:58); Santucho logra ver plasmada su iniciativa editorial recién en la década del 1970 con el órgano de difusión del PRT - ERP era un periódico llamado "El Combatiente" y la revista "Estrella Roja" que llego a tener una tirada de 30.000 ejemplares. Este medio era idóneo para llegar a los jóvenes y a los estudiantes secundarios y universitarios (probablemente Santucho consideró de suma importancia la intervención del estudiantado del ejemplo de la revolución cubana), pero también a los trabajadores a quienes se le repartía los ejemplares a la salida de las fábricas (Brienza, 2006; Getselteris, 2015; Mangiantini, 2014; Osatinsky, 2012; Santucho, 1964, 1966). 


\section{CONCLUSIONES}

Tal como se pudo apreciar a lo largo del presente análisis del texto "cuatro tesis sobre el norte argentino”, el autor realiza una tarea analítica sobre el terreno mismo de la región donde se cultiva la caña de azúcar y donde es explotada su clase obrera. Esta clase también ha sufrido un proceso de "descampesinización” con el correr de los cambios generacionales y los avances tecnológicos, pero también se dieron procesos de reproducción de clase que les permitieron continuar subsistiendo con identidad de clase. A pesar del paso del tiempo, y la disminución de su número, continúan siendo un factor importante en la dinámica sociopolítica de la región, pero principalmente en la provincia de Tucumán.

En la actualidad los trabajadores cañeros siguen en inferioridad de condiciones, salarios y precariedad laboral, puesto que el trabajo es altamente nocivo para la salud de los cosechadores (la caña de azúcar posee vetas filosas que producen cortes en las extremidades de los trabajadores) puesto que la vinaza (desecho de la caña de azúcar) es volátil y muy contaminante. Al marguen de esta situación es de destacar que los trabajadores gozan de una excelente obra social, O.S.P.I.A., que les permite sobrellevar de mejor manera las vicisitudes de su ambiente laboral. Por todas estas razones el autor brinda un trazado de un plan de acciones sobre cada clase social en particular dando los motivos de porque debe ser la clase obrera de la caña de azúcar la que debe liderar el proceso revolucionario que los demás componentes sociales deberán seguir en su lucha revolucionaria.

Por otra parte, es de destacar los severos daños ambientales que la industria azucarera produce, los cuales se hacen sentir hasta en la misma ciudad dado que los ingenios se encuentran en las cercanías produciendo daños a la salud, no solo de los propios trabajadores sino también en una importante parte de la población aledaña. Es de comprender que en la contemporaneidad del autor y de la escritura de las cuatro tesis la cuestión ambiental no haya tenido tanta relevancia como la tiene en la actualidad. Lo realmente destacable del texto resulta del análisis y la preocupación del autor por una de las clases sociales más olvidadas del espectro laboral rural.

\section{REFERENCIAS BIBLIOGRÁFICAS}

Anónimo (s/f). Los campesinos en la agroindustria cañera. (pp. 145 - 171) Sin datos. Brienza, H (2006). Mario R. Santucho. La guerrilla de izquierda. Capital Intelectual Castiglione, A (2012). Historia de Santiago del Estero. Muy Noble Ciudad (Siglos XVI, XVII y XVIII). Autor

Floria, C. y García Belsunce, C. (1992) Historia de los argentinos. Larousse

Garay, L. (2008) Camino Real. (caminos del tiempo). 1 Ed. El Liberal

Getselteris, G (2015). Desde el monte. La compañía de monte vencerá. Nuestra América.

Mangiantini, M (2014) El trotskismo y el debate en torno a la lucha armada. Moreno, Santucho y la ruptura del PRT. El topo blindado 
Osatinsky, A (2012). Estructura productiva, actividad azucarera y mercado de trabajo en Tucumán (1930-1970). Revista de Historia Americana y Argentina, (47), 41-71 Universidad Nacional de Cuyo. Mendoza. Argentina.

Santilli, S (2007). En búsqueda de una identidad revolucionaria. Revista Cuadernos de $\mathrm{H}$ Ideas, Año 1, $\mathrm{N}^{\circ}$ 1. (p. 91-114) Universidad Nacional de La Plata. Argentina

Santucho, F (2016). Francisco Rene Santucho. Obras completas. Barco edita

Santucho, M (2008). Mario Roberto Santucho. Mi padre, el revolucionario místico. Dunken Santucho, B (2009). Nosotros, los Santucho. El autor

Santucho, M (1966). Cuatro tesis sobre el Norte argentino. Recuperado de: http://eltopoblindado.com/files/Publicaciones/Organizaciones\%20PoliticoMilitares\%20de\%20origen\%2oMarxista/PRT\%2oPartido\%2oRevolucionario\%2ode \%2olos\%2oTrabajadores/II.\%20PRT/Documentos/1966\%20abril.\%204\%20Tesis\%2 osobre\%20el\%2onorte\%20argentino-Baja.pdf

Santucho, M (1964). El Proletariado Rural detonante de la revolución argentina. Tesis políticas del FRIP

Rouquie, A (1982). Argentina hoy. Siglo XXI

Sicilia, L (2007). José Carlos Mariátegui. Un marxismo indígena. Capital Intelectual

Sidicaro, R (1982). "Poder y crisis de la gran burguesía agraria" en Rouquie, A (1982). (comp) Argentina hoy. Siglo XXI

Terán, O (2007). "Un socialista en los márgenes". en Sicilia, L (2007). José Carlos Mariátegui. Un marxismo indígena. Capital Intelectual

Volonté, F. (2014). De Dimensión al FRiP: La empresa cultural y la política revolucionaria. VIII Jornadas de Sociología de la UNLP, 3 al 5 de diciembre de 2014, Ensenada, Argentina. En Memoria Académica. Disponible en: http://www.memoria.fahce.unlp.edu.ar/trab_eventos/ev.4321/ev.4321.pdf 